\title{
Blockchain for Next Generation Services in Banking and Finance: Cost, Benefit, Risk and Opportunity Analysis
}

\author{
Mohamad Osmani \\ College of Business and Economics, Qatar University, Doha, Qatar \\ Ramzi El-Haddadeh \\ College of Business and Economics, Qatar University, Doha, Qatar \\ Nitham Hindi \\ College of Business and Economics, Qatar University, Doha, Qatar
}

Marijn Janssen

Faculty of Technology, Policy and Management, Delft University of Technology, Delft, The Netherlands

\section{Vishanth Weerakkody}

Faculty of Management and Law, University of Bradford, Emm Lane, Bradford, UK

\begin{abstract}
Purpose - The purpose of this paper is to help in providing a better understanding of the application of blockchain technology in the context of the banking and finance sectors. The aim is to outline blockchain's benefits, opportunities, costs, risks as well as challenges of the technology in the context of banking and finance services

Design/methodology/approach - Careful examination of the extant literature, including utilising relevant academic-based research databases has been carried out. It covered reviewing various research contributions published in peer-reviewed journals, academic reports, as well as technical reports to help in identifying related benefits, opportunities, costs, and risks.
\end{abstract}

Findings - The findings reveal that there are limited contributions in utilising blockchain in the banking and finance sectors when compared with other sectors. As such, the study highlighted the relevant perspective of benefits, opportunities, costs, and risks within such sectors. 
Practical implications - This study helps in offering a focal point to banking and financial sector managers and decision-makers for realising the benefits of blockchain technology as well as developing strategies and programmes to overcome the identified challenges.

Originality/value - This study highlights the need for a holistic understanding of the various aspects of cost, benefits, risk and opportunities to create blockchain applications that work for banking and finance sectors

Keywords: blockchain, cost, benefit, risk, opportunity, banking and finance Article type: Literature review

\section{INTRODUCTION}

Over the years, the use of emergent digital innovative technologies, through telebanking, online and mobile banking and fintech, has contributed towards offering new experiences. In this regard, convenience, availability, speed, efficiency, effectiveness and transparency of banking and financial processes have enabled the sector to tackle some of the common challenges associated with facilitating transactions across various sectors (Peters \& Panyi, 2016; Frame and White, 2014). The emergence of blockchain technology has been heralded as the next revolution that will transform the shape and size of the banking and finance industry and the way business transactions are conducted (Ceremeno, 2016). Blockchain technology is focused on having an open, universally accessible decentralised ledger for establishing trust in an unsecured environment without relying on a third-party. The ledger contains the shared and agreed-upon state of the blockchain, including a list of all past transactions that are immutable. Moreover, it can also be utilised along with other 
technologies, such as encryption, business rules and identity management, in order to make such technology fit for the challenges at hand (Van Engelenburg et al., 2018).

Furthermore, blockchain has also the potential to disrupt the banking sector by exploiting it across various financial services. As such, it includes facilitating global money remittance, smart contracts, automated banking ledgers and digital assets (Peters \& Panayi, 2016). It can transform a considerable number of existing traditional banking services through improving transaction security and expediting transfers at a lower cost (Lee and Shin, 2017). Therefore, it offers the opportunity to help in enhancing issues surrounding transparency, trust and privacy for relevant stakeholders. Nonetheless, as much as blockchain has brought opportunities for organisations, it is pivotal to realise that there will be several challenges and complexities across technical, regulatory, and adoption-related areas (Attaran and Gunasekaran, 2019). Recent events such as digital currency theft and cybersecurity breaches have demonstrated the high-level of risks related to the use of blockchain technologies in banking and finance (Deshpande et al., 2017; Attaran and Gunasekaran, 2019).

While exploiting the potential of new-disruptive technologies, specifically blockchain, it is equally vital to comprehend the potential benefits, risk and challenges associated with them to mitigate risks and avoid the technical, social and political consequences of failure. Therefore, this study aims to outline blockchain's benefits, opportunities, costs, risks, as well as challenges of technology in the context of banking and finance services. The remainder of this paper is organised as follows: section two presents the research methods followed by providing state of the art review of blockchain 
technology within the banking and finance sectors. This is followed by highlighting the overall challenges of blockchain technology in section three. After that, in section four, cost, benefit, risk and opportunities framework is then introduced to examine blockchain technology within the banking and finance sector. Finally, section five presents the discussions and concluding remarks of the study.

\section{Methodology}

There are various different approaches to conducting a literature review and can be classified into three broad types (see table 1): systematic review, the semi-systematic review, and the integrative review (Snyder, 2019). As mentioned in the previous section, the aim of this study is to help in providing a better understanding of the application of blockchain technology in the context of the banking and finance sectors. To achieve the purpose of this review, integrative review is the most helpful and appropriate to reach the aim of this study. By adapting integrative review approach, this study can assess, critique, and synthesize the literature on Blockchain technology that enables to develop a chasification of important challenges. Relevant literature on blockchain's benefits, opportunities, costs, risks as well as challenges of the technology in the context of banking and finance services was extracted from Scopus, Web of Science and Scholar Google. The search criteria included the following keyword combinations: (Blockchain OR Block chain) AND '(Banking and Finance' OR Fintech) AND (Challenges OR Benefits OR Costs OR Benefits OR Risks). The extracted literature and secondary research is then used to capture the benefits and challenges associated in block-chain and then develope a blockchain 
analysis framework and taxonomy that identified and cluster the key influencing issues, including benefits, challenges, opportunities and risks for Banking and Finance Services.

\begin{tabular}{ll}
\hline Literature Review & Description \\
Approaches &
\end{tabular}

Systematic Review

(Davis et al., 2014;

Liberati et al., 2009)
A systematic review is defined as a tool and process of study to classify and critically evaluate relevant research and to collect and analyze data from such research. A meta-analysis is a statistical tool for integrating findings from various studies to measure and compare and classify trends, disagreements or relationships that occur on the same topic in the context of multiple studies.
Semi-systematic analysis explores how research has evolved over time within a chosen field, or how a topic has developed across research traditions. Thematic or content analysis is a technique commonly used to identify themes, theoretical perspectives or common issues within a specific research discipline.

The aim of the integrative review is to assess, criticize and synthesize research literature in such a way that new theoretical frameworks and perspectives can emerge. In the case of emerging themes, the aim is more to create initial or preliminary conceptualizations and theoretical models than to review old models. An integrative review method will result in the advancement of knowledge and will contribute to the literature in the form of development of theoretical frameworks and taxonomy or classification.

Table 1: Literature Review Methods

\section{BLOCKCHAIN FOR NEXT GENERATION BANKING AND FINANCIAL SERVICES}

Financial technologies have created a new paradigm shift in driving innovation in the financial sector and Blockchain technology is a significant part of this transformation (Lee and Shin, 2017). While there has been a wide range of traditional banking products from payments to investment services, blockchain technology has 
challenged this through offering an innovative, more secured, and faster transfers at lower costs (Lee and Shin, 2017). Blockchain technology can be explained as " $A$ blockchain is essentially a distributed database of records or public ledger of all transactions or digital events that have been executed and shared among participating parties. Each transaction in the public ledger is verified by the consensus of a majority of the participants in the system. Once entered, information can never be erased. The blockchain contains a certain and verifiable record of every single transaction ever made" (Crosby et al., 2016, p. 7). As such, this will help in eliminating centralised points of vulnerability, which cybercriminals can potentially exploit. At the same time, making data manipulation is exceptionally impracticable (Mason, 2017; Mearian, 2017).

The Blockchain technology underpinning cryptocurrencies such as Bitcoin, Ethereum and other alternative coins was perceived by most of the banks with much criticism and scepticism (Attaran and Gunasekaran, 2019). However, this has started to change recently and became a prevalent topic within the banking and finance sectors. The primary reason is that it is far less expensive, and the transactions processing time is significantly faster. Banks have been looking at ways to use the Blockchain technology for clearing and settlement, trade finance and syndicated loans (Arnold, 2017). As a result, this will enable banks to process payments more quickly and accurately while reducing transaction-processing costs. Accenture digital (2017) interviewed thirty-two commercial banking professionals to study the potential of blockchain technology, and the results indicated that nine in ten executives said their bank is currently exploring the use of blockchain. McKinsey also surveyed banking executives globally and found that around half of executives think that blockchain will 
have a significant impact within three years (Ngai, 2016). Likewise, IBM has indicated that, in 4 years, $66 \%$ of banks will have commercial blockchain in four years (Shen, 2016).

Since 2015 , several major international financial institutions have begun to prepare proposals for the blockchain sector. For example, Goldman Sachs, J.P. Morgan and other banking giants have all established their blockchain laboratories, working in close collaboration with blockchain platforms, and published a series of studies on this topic (Guo and Liang, 2016). J. P. Morgan with two global partners, Royal Bank of Canada and Australia and New Zealand Banking Group Limited, announced the launch of the largest blockchain payments networks called Interbank Information Network (INN) (ibid). The new initiative can use blockchain technology to minimise friction in the global payments process, and hence, allow payments to reach beneficiaries faster with fewer steps and better security. Furthermore, IIN will enhance the client experience, decreasing the amount of time from weeks to hours and costs linked with settling payment delays (Mearian, 2017). By leveraging blockchain technology, IIN will aim to significantly reduce the number of participants currently needed to respond to compliance and other data-related inquiries that delay payments.

Additionally, various national stock exchanges, such as the Nasdaq Stock Market and the New York Stock Exchange have also conducted in-depth research on blockchain technology. In 2015, Nasdaq announced that it had completed its first securities transaction using the blockchain transaction platform Linq (Zhu et al., 2016). Furthermore, the US Depository Trust \& Clearing Corporation, Visa, the Society for Worldwide Interbank Financial Telecommunication, and other financial entities have also expanded their plans in the blockchain technology sector (Guo and Liang, 2016). 
Furthermore, most recently American Express introduced instant blockchain-based payments using Ripple, a fintech startup, marking one of the first major users of the technology. These discussions highlight that the world's biggest banks are looking for opportunities in this area by researching innovative blockchain applications. Furthermore, the banking and finance sector no longer see blockchain technology as a threat to traditional business models (Crosby et al., 2016).

Nonetheless, governments across the globe have foreseen the benefits in utilising innovative blockchain technology within its services. In this regard, Gibraltar is the first country in the world that will introduce a customised licence for fintech firms using blockchain distributed ledger technology to attract start-ups. Other developed nations such as the US, the UK, and Japan, have paid close attention to the development of blockchains and investigated their application in various fields. Similarly, China, Russia, India, South Africa, and other countries have also successively initiated research on blockchain technology (Guo and Liang, 2016). However, many cities in Europe, the United States and Asia have yet to take the regulatory step, mainly because the adoption of blockchain technology is not systemically significant enough to warrant specific regulation. The decentralisation and self-governance of blockchain technology are considered a risk, which reduces the idea of regulation and has a critical impact on the existing system. Therefore, blockchain regulation is necessary and should be formulated sooner rather than later (Guo and Liang, 2016). According to Cermeno (2016), many critical regulatory challenges need to overcome before blockchain technology can be used in the financial sector.

\section{THE STATUS QUO OF BLOCKCHAIN TECHNOLOGY IN BANKING AND FINANCE SERVICES}


The introduction of any new innovative technology would offer various opportunities as well as challenges (see table 2) that can considerably influence the adoption process (El-Haddadeh, 2019). In the context of blockchain technology, one of the main critical challenges can be associated with regulatory issues. While the technology itself, by definition, does not object to being regulated, the diversified use of the technology demands such matter (including cryptocurrencies, blockchains, shared ledgers, smart contracts). Therefore, depending on specifics of the financial processes are being offered on the blockchain (such as payments, lending, investment), appropriate regulation mechanisms will need to be applied. In this regard and at the global level, policymakers and regulators have been mainly focusing on regulating the use of cryptocurrencies to avoid taxation and criminal activities (Cermeno, 2016). While some countries consider cryptocurrencies as digital money, others treat them as commodities. In 2015, the European Court of Justice (ECJ) ruling identified cryptocurrency transactions are exempted from VAT and treated it as money or currency (Court of Justice of the European Union, 2015). As such, this could be recognised as a mechanism influencing the development rate of blockchain technology. Therefore, regulatory approaches would need to cleverly balance against its innovative spirits while recognising the possibility of the technology unintentionally contributing to systemic risks to the financial system (Yeoh, 2017). Yeoh (2017) claimed that there are challenges to broader blockchain adoption and use despite the opportunities it offers. He argued that blockchain relies on collaborative governance to provide trust in the financial markets to ensure that all play by agreed rules. The absence of such governance has been one of the main reasons behind various blockchain cybercrimes and other criminal activities (Attaran and Gunasekaran, 2019; 
Crosby et al., 2016). Such governance with right policies, procedures and mechanisms as well as enforcements are needed to realise the real societal benefits of blockchains. Harwood-Jones (2016) also claimed that blockchain's broader and deeper applications are potentially constrained by limitations posed by technical and scalability challenges, business model challenges, scandals and public perception, government rules and privacy challenges. Regulation concerns laws are designed to control behaviour, while governance concerns stewardship, collaboration and incentives to act on common interests. In this respect, governments have been genuinely expected to regulate technologies such as blockchain and at the same time function as a collaborative peer to other constituents of society rather than as the heavy hand of the law (Tapscott and Tapscott, 2016). It can be done by participating as players in a bottom-up governance ecosystem instead of as enforcements of top-down regimes of control (Yeoh, 2017).

The financial instability derived from the decentralised nature of blockchain technology has created several challenges across various industries and government authorities (European Securities and Markets Authorities, 2017; Lee and Shin, 2018). In this respect, regulatory activities can be expected to help in providing the required environment that can facilitate the broader adoption, specifically in the banking sector (Fan, 2018; Kshetri, 2018; Larios-Hernández, 2017). By doing so, it will help maintain the required safeguards towards the sustainability and continuity of blockchain within this industry and beyond. From a system infrastructure perspective, the disruptive nature of blockchain technology has created a paradigm shift in the banking and finance ecosystems (Pazaitis et al., 2017; Kshetri, 2017). The innovative approach, based on utilising peer-to-peer distributed networks while applying open-source 
cryptographic protocol, has demonstrated its potential with fast, cost-effective, and

secure transfers of financials and assets across the globe (Mansfield-Devine, 2017).

\begin{tabular}{|c|c|}
\hline Challenges & References \\
\hline Regulatory challenges & Cermeno (2016) Guo and Liang, 2016 \\
\hline $\begin{array}{l}\text { Lack of collaborative governance to provide } \\
\text { trust in the financial markets }\end{array}$ & $\begin{array}{l}\text { Attaran and Gunasekaran, 2019; Crosby et } \\
\text { al., 2016; Yeoh, 2017; Zhui, } 216\end{array}$ \\
\hline Technical and scalability challenges & $\begin{array}{l}\text { Harwood-Jones (2016); Pennathur, 2001; } \\
\text { Bauer and Hein, } 2006\end{array}$ \\
\hline Business model challenges, & Harwood-Jones (2016) \\
\hline Scandals and public perception, & Harwood-Jones (2016) \\
\hline Government rules and privacy challenges & $\begin{array}{l}\text { Harwood-Jones (2016); Pennathur, 2001; } \\
\text { Bauer and Hein, } 2006\end{array}$ \\
\hline Interoperability & $\begin{array}{l}\text { Pazaitis et al., 2017; Kshetri, 2018; Kshetri, } \\
2017\end{array}$ \\
\hline Security and privacy of data & $\begin{array}{l}\text { Deshpande et al. (2017); Pennathur, 2001; } \\
\text { Bauer and Hein, } 2006\end{array}$ \\
\hline Integrity of data and secure encryption, & Deshpande et al. (2017) \\
\hline Energy cost of the technology & $\begin{array}{l}\text { Deshpande et al. (2017); Caplen, 2018; } \\
\text { Bauerle, 2018; Zheng et al., 2018; Marr, } \\
\text { 2017; Hillsberg, 2018; Hassani et al., } 2018\end{array}$ \\
\hline Lack of clarity regarding smart contracts & Deshpande et al. (2017) \\
\hline Perceived risks in early adoption & $\begin{array}{l}\text { Deshpande et al. (2017); Atzori, 2015; } \\
\text { Bandt et al. 2012; }\end{array}$ \\
\hline Disruption to existing industry practice, & Deshpande et al. (2017) \\
\hline $\begin{array}{l}\text { Insufficient evidence on business gains and } \\
\text { broader economic impact, }\end{array}$ & Deshpande et al. (2017) \\
\hline $\begin{array}{l}\text { Lack of clarity on how the technology } \\
\text { would be governed, }\end{array}$ & $\begin{array}{l}\text { Deshpande et al. (2017); Attaran and } \\
\text { Gunasekaran, 2019; Crosby et al., 2016; } \\
\text { Yeoh, } 2017\end{array}$ \\
\hline Uncertainty around regulation & $\begin{array}{l}\text { Deshpande et al. (2017); Cermeno (2016) } \\
\text { Guo and Liang, } 2016\end{array}$ \\
\hline $\begin{array}{l}\text { Multiple non-interoperable } \\
\text { implementations and resulting } \\
\text { fragmentation }\end{array}$ & $\begin{array}{l}\text { Deshpande et al. (2017); Pazaitis et al., } \\
\text { 2017; Kshetri, 2018; Kshetri, } 2017\end{array}$ \\
\hline $\begin{array}{l}\text { Re-engineering of processes and } \\
\text { integration with legacy systems }\end{array}$ & Deshpande et al. (2017) \\
\hline $\begin{array}{l}\text { Blockchain technology as a threat to } \\
\text { traditional business models }\end{array}$ & al., 2016 \\
\hline
\end{tabular}

Table 2: Challenges of Blockchain Technology

Nonetheless, interoperability has ascended as a challenge, specifically for banks, in

facilitating the process of maintaining the required operation at internal and external

levels (European Securities and Markets Authorities, 2017). At the internal level, re-

engineering of processes and integration with legacy systems is a challenge which 
banks will need to acknowledge as part of their implementation process. On the other hand, enabling a functional cross-chain depends on retaining a rigorous, trustworthy relationship across various blockchain applications and platforms (Pazaitis et al., 2017; Kshetri, 2018; Kshetri, 2017). As such, various financial institutions have realised the need for utilising conventional technology standards and protocols in order to offer necessary support of a seamless distributed digital transaction process. (Kshetri, 2018) Furthermore, the decentralised, transparent, equality and accountability have driven nature of this disruptive technology has created some new settings where individuals can be less dependent on controlled, sometimes inefficient, services offered through associated service providers (Al-Saqaf \& Seidler, 2017; Vranken, 2017). As a result, it has been shaping a new and unprecedented environment which is impacting the socioeconomic as well as the cultural settings. Hence, this has created the need for realising how this innovative technology can be integrated within businesses strategies and individuals' activities in order to understand its societal impact (MarsalLlacuna, 2018). For the banking industry, the increased levels of trusts, based on the distributed ledger network nodes and associated transparency, and the faster and more cost-effective financial transfers can contribute towards providing a convincing argument for customers towards speedy participation (Kshetri, 2018; European Securities and Markets Authorities, 2017). According to Deshpande et al. (2017), some of the main challenges facing blockchain technology are: lack of clarity on the terminology and perceived immaturity of the technology; perceived risks in early adoption and likely disruption to existing industry practice, insufficient evidence on business gains and broader economic impact, lack of clarity on how the technology would be governed, uncertainty around regulation, multiple non-interoperable 
implementations and resulting fragmentation, maintaining security and privacy of data, ensuring integrity of data and secure encryption, energy-intensive nature of the technology, lack of clarity regarding smart contracts and how to implement them through Blockchain.

\section{BLOCKCHAIN FOR BANKING AND FINANCE: COST, BENEFIT, RISK AND OPPORTUNITY ANALYSIS}

This study used SWOT theory as a theoretical lens to develop cost, benefit, risk and opportunity framework to understand the determinants of blockchain adoption. SWOT analysis is a short form for strengths, weaknesses, opportunities, and threats and is a structured planning method that evaluates those four elements of an organisation, services or products. In the current study (see figure 1, blockchain strength relates to benefits, weaknesses to costs, threats to risk and opportunities are the same (Osman et al., 2014). Costs of blockchain technology are related to operating costs such as transaction costs, energy and storage costs and the benefits are related to the technical aspects such as privacy, transparency, security, trust and faster transactions. While the risk of using blockchain technology is referred to as technical, operational and regulatory legal risks, opportunities are related to whether the market would embrace the technology or not. 

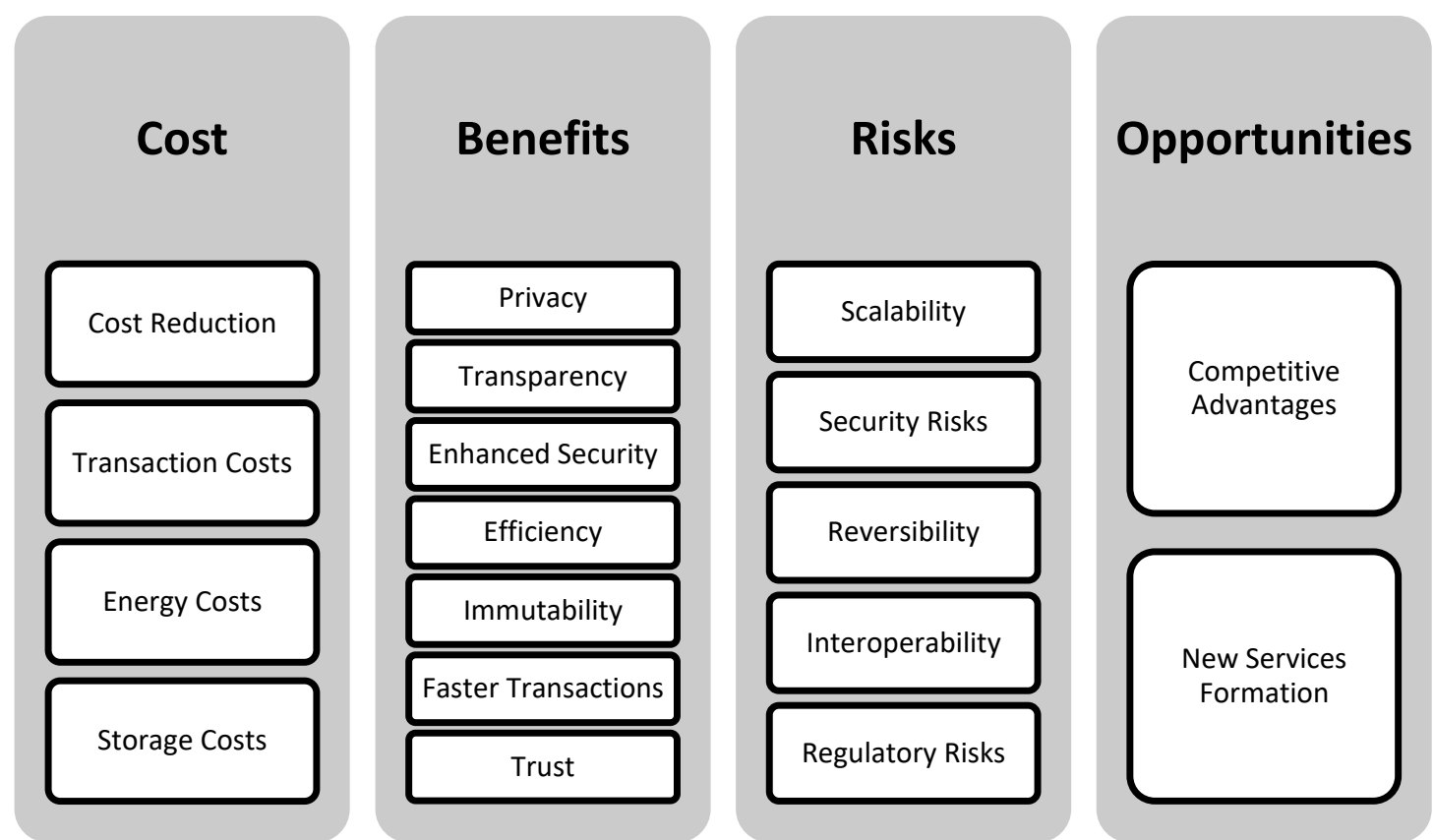

Figure 1: Cost, Benefit, Risks, and Opportunity Analysis Framework

\subsection{Examining Blockchain Costs for Banking and Finance Services}

Cost reduction will always play an influential role in the adoption of blockchain technology (Hassani et al., 2018). Accenture (2017) suggested that blockchain-based solutions could help banks save up to 8 billion USD, while Santandar report claimed that they could generate cost savings of up to 20 billion USD per annum (Meola, 2017). Blockchain technology can reduce infrastructure costs by $30 \%$ for banks and will result in cost savings of 8-12 billion USD annually (Ngo, 2017). By making the banking transaction more efficient by eliminating the need for intermediaries and associated charges will result in further cost reductions (Marr, 2017; Hillsberg, 2018).

The operating costs of using blockchain technology for banks can be classified into three factors: transaction costs, energy costs, and storage costs. The cost of storage is a rising concern for blockchain technology in banking, for example, it is expected that in the long term storage cost per gigabyte for a Bitcoin node will exceed 22 million USD (Bloomberg, 2018). The increase in the amount of energy required to assist 
blockchain algorithms is another major challenge for the banking sector, for example, if cryptocurrencies were to grow to $5 \%$ of global money supply, it is estimated that the processing would require $10 \%$ of the energy consumed by China (Caplen, 2018). Finally, transaction costs are influenced with both cost of storage and energy costs, for example; currently, each bitcoin transaction costs about 0.20 USD (Bauerle, 2018) and as a result of electricity costs, the single transaction cost for Bitcoin can vary between 75-160 USD (Bloomberg, 2018). Zheng et al. (2018) also claimed that energy costs and storage cost would rise as the transaction volume increases, and a blockchain database must store data indefinitely, which means that the database will grow substantially over time, as will the storage costs.

\subsection{Exploring Blockchain Benefits for Banking and Finance Services}

Blockchain provides Banks with operational benefits such as privacy, transparency, enhanced security, cost savings, immutability and faster transactions (Mendling et al., 2017; Lansiti and Lakhani, 2017; Kiayias and Panagiotakos, 2016; Kosba et al., 2016; Zyskind and Nathan, 2015). Park and Park (2017) claimed that using blockchain provides higher security compared to storing all data in a central database and will prevent damage from attacks on the database. Besides, blockchain has an openness attribute, and as a result, it provides transparency in data when applied to an area requiring the disclosure of data. Therefore, due to such benefits, blockchain can be utilised in diverse areas, including the financial sector and its applications are expected to expand. Wang et al., 2019 mentioned that blockchain is a distributed technology that increases the visibility and transparency of the stored, and as an immutable ledger, blockchain ensures a single version of the truth that helps to build trust in the stored information. Queiroz and Wamba (2019) also argued that blockchain 
transparency is a significant predictor of the behavioural intention to use blockchain. Furthermore, Queiroz and Wamba (2019) argued that transparency is strengthened because the transactions are shared across the network, together with any useful information, thus enabling all network actors to informed of all in due time, also resulting in creating trust. Clohessy and Acton (2019) examined the primary reasons of organisations adopting blockchain and found that the intention to adopt was related to benefits such as reduced costs, enhanced security, efficiency and transparency of the transaction.

\subsection{Vindicating Blockchain Risks for Banking and Finance Services}

Banks adopting new technologies such as blockchain must be prepared to tackle technical and operational risk, regulatory and legal risk as well as reputation risk that may arise from these (Pennathur, 2001; Bauer and Hein, 2006; Deshpande et al., 2017) The Basel committee report defines operational risk as the potential for loss due to significant deficiencies in system reliability and integrity. The Federal Deposit Insurance Company (FDIC, 2000) describes this risk as hardware/software failures, disruptions, protections, systems or database compromise. Operational risk is mainly arising from external hacking. Hackers may obtain confidential information by manipulating data or altering account balances (Attaran and Gunasekaran, 2019). For example, when small banks outsource their web operations, internal controls may not cover vendors who establish web-based functionalities (Pennathur, 2001). Also, customers may intentionally or unintentionally misuse the website leading to an increase in operational risk. Overall, inadequate technical and operational controls, policies and procedures can create operational and security risk that can lead to theft and fraud in a digital environment (De Fontnouvelle and Perry 2005; Cummins et al. 
2006; Gillet et al. 2010; Deshpande et al., 2017). These issues can ultimately impact on the reputation of the banks, a critical risk, as relationships in the sector are based on trust (Fiordelisi et al. 2014).

From a technical point of view, several issues need to be investigated and taken into consideration that may potentially impact the use of blockchain technology to deliver sector-leading banking and finance processes. Issues such as scalability, security and interoperability and reversibility are some of the technological challenges highlighted in the existing literature (e.g. Vukolić, 2015; Ølnes, 2016; Cermeño, 2016) that the banking and finance sector could face when using blockchain technology. When it comes to the blockchain as a tool for regulators and supervisors, research claims (e.g. Atzori, 2015; Cermeño, 2016, Swan, 2019) that it brings about fundamental advantages to the financial services regulators. Nevertheless, there also remains regulatory challenges with the blockchain initiatives as its applications (such as payments, lending, investment) are currently immature and in exploratory phases in the financial services sector which make it even more complex and challenging to undertake its regulation. Legal risks arise due to ambiguity and uncertainty related to legal rights (Pennathur, 2001; Swan, 2019). This risk is primarily amplified through internet-based banking activities. Legal issues arising from customer privacy and disclosure, money laundering and liability concerns of banks which have links to other websites. Computer theft can raise the concerns of banks about their liability for loss of customer funds. The legal nature including territoriality and liability, legal recognition of blockchain as a tamper-proof source, legality for treatment on shared information and regulatory reporting information standards are few regulatory issues extracted from the existing literature to highlight some of the challenges that the 
banking and finance sector could face using blockchain technology.

\subsection{Exploiting Blockchain Opportunities for Banking and Finance Services}

The blockchain technology is becoming attractive in the operation of commercial banks all over the world as it ensures them the opportunity to gain competitive advantages of financial contracts based on reduction of the costs on economic agents' interaction, provision of information transparency and effective control over operational risks and controlling costs on the network and financial transactions (Vovchenko et al., 2017). Yudina (2016) argued that the use of digital technologies such as blockchain would provide sustainable competitive advantages for business development in terms of economy virtualisation. The blockchain technology competitive advantages are not only the ability to expand the tools of operations but also the formation of the new service in the future (Vovchenko et al., 2017). The global financial services market is becoming highly competitive. Therefore, banks are inclined to apply new innovative technologies such as blockchain to gain a competitive advantage over their competitors successfully.

\section{DISCUSSIONS AND CONCLUDING REMARKS}

When examining the literature, various studies have offered insights into the challenges of adopting new disruptive technologies in banking and finance sector such as mobile banking and cryptocurrency (Guo and Liang, 2016; Larios-Hernández, 2017; Lee and Shin, 2017). Although online and mobile banking is already well established, there are still adoption challenges which need to be overcome before digital banking becomes well established (Pazaitis et al., 2017; Kshetri, 2017). The use of technology in the banking and finance sector is creating a new paradigm shift in which emergent technology is driving innovation in the field. Currently, the financial industry is 
(Lee and Shin, 2017). Blockchain products are challenging a wide range of traditional banking products from payments to investment advice. Lipton et al. (2016) argued that blockchain might be the end of a 'bank' as an organisation, although the function of banking and the need for government regulation will remain. Also, blockchain might make currencies global instead of country-based, as crypto currents are not geographical bound. While there are all kinds of doom scenarios, there is consensus that the banking and financial industry will change due to these technology developments.

\begin{tabular}{|c|c|c|c|}
\hline & Factors & Description & References \\
\hline \multirow{4}{*}{$\ddot{\breve{u}}$} & Cost Reduction & $\begin{array}{l}\text { Blockchain can help in making banking transaction more } \\
\text { productive by eliminating the need for intermediaries } \\
\text { resulting cost reduction }\end{array}$ & \multirow{4}{*}{$\begin{array}{l}\text { Caplen, 2018; } \\
\text { Bauerle, 2018; } \\
\text { Zheng et al., 2018; } \\
\text { Marr, 2017; } \\
\text { Hillsberg, 2018; } \\
\text { Hassani et al., } 2018\end{array}$} \\
\hline & $\begin{array}{l}\text { Transaction } \\
\text { Costs }\end{array}$ & $\begin{array}{l}\text { The future rise in energy costs and storage cost will increase } \\
\text { the transaction cost of blockchain impacting the cost per } \\
\text { transaction. }\end{array}$ & \\
\hline & Energy Costs & $\begin{array}{l}\text { The increase in transactions volumes will rise energy required } \\
\text { to assist blockchain algorithms throughout the performed } \\
\text { financial transactions }\end{array}$ & \\
\hline & Storage Costs & $\begin{array}{l}\text { Blockchain database must store data indefinitely, which } \\
\text { means that the database will grow substantially over time, as } \\
\text { will the storage costs for relevant financial institutions. }\end{array}$ & \\
\hline \multirow{7}{*}{ 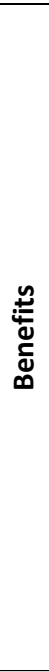 } & Privacy & $\begin{array}{l}\text { Blockchain transactions can provide users with better } \\
\text { privacy, allowing users to own their data and not allowing } \\
\text { third-party intermediaries to misuse and obtain data. }\end{array}$ & \multirow{7}{*}{$\begin{array}{l}\text { Wang et al., 2019; } \\
\text { Clohessy and } \\
\text { Acton, 2019; } \\
\text { Queiroz and } \\
\text { Wamba, 2019; } \\
\text { Mendling et al., } \\
\text { 2017; Lansiti and } \\
\text { Lakhani, 2017; } \\
\text { Kiayias and } \\
\text { Panagiotakos, } \\
\text { 2016; Kosba et al., } \\
\text { 2016; Zyskind and } \\
\text { Nathan, 2015; } \\
\text { Mainelli \& Smith, } \\
\text { 2015; Mcai \& Zhui, } \\
\text { 216 }\end{array}$} \\
\hline & Transparency & $\begin{array}{l}\text { Transparency is strengthened because the transactions are } \\
\text { shared across the network }\end{array}$ & \\
\hline & $\begin{array}{l}\text { Enhanced } \\
\text { Security }\end{array}$ & $\begin{array}{l}\text { Blockchain provides financial institutions with higher security } \\
\text { compared to storing all data in a central database and } \\
\text { prevent damage from attacks on the database. }\end{array}$ & \\
\hline & Efficiency & Blockchain offers banks a quick reduction in overhead costs & \\
\hline & Immutability & $\begin{array}{l}\text { Transaction history in the blockchain cannot be modified } \\
\text { since blockchain ledger can remain permanent and } \\
\text { unaltered. }\end{array}$ & \\
\hline & $\begin{array}{l}\text { Faster } \\
\text { Transactions }\end{array}$ & $\begin{array}{l}\text { Blockchain will allow payments to reach beneficiaries faster } \\
\text { with fewer steps }\end{array}$ & \\
\hline & Trust & $\begin{array}{l}\text { Blockchain relies on collaborative governance to provide } \\
\text { trust in the financial markets to ensure that all play by agreed } \\
\text { rules. }\end{array}$ & \\
\hline \multirow[t]{2}{*}{$\overline{\frac{\bar{a}}{x}}$} & Scalability & $\begin{array}{l}\text { In comparison to } 1000 \text { traditional banking transactions per } \\
\text { second, blockchain can process around five transactions per } \\
\text { second on average. This gap implies a considerable challenge } \\
\text { for the adoption of blockchain for banking on a global scale. }\end{array}$ & \multirow{2}{*}{$\begin{array}{l}\text { Pennathur, 2001; } \\
\text { Bauer and Hein, } \\
\text { 2006; Pana et al. } \\
\text { 2015; De } \\
\text { Fontnouvelle and } \\
\text { Perry 2005; }\end{array}$} \\
\hline & Security Risks & $\begin{array}{l}\text { Hackers may obtain confidential information by manipulating } \\
\text { data or altering account balances }\end{array}$ & \\
\hline
\end{tabular}




\begin{tabular}{|c|c|c|c|}
\hline & Reversibility & $\begin{array}{l}\text { Financial institutions can not recall a mistaken transaction } \\
\text { since on the blockchain transactions are irreversible and final. }\end{array}$ & \multirow{3}{*}{$\begin{array}{l}\text { Cummins et al. } \\
\text { 2006; Gillet et al. } \\
\text { 2010; Vukolić, } \\
\text { 2015; Ølnes, 2016; } \\
\text { Cermeño, 2016; } \\
\text { Atzori, 2015; Bandt } \\
\text { et al. 2012; } \\
\text { Deshpande et al., } \\
2017\end{array}$} \\
\hline & Interoperability & $\begin{array}{l}\text { There is limited interoperability between different networks } \\
\text { in blockchain, which is crucial for financial institutions to } \\
\text { transact with each other. }\end{array}$ & \\
\hline & Regulatory Risks & $\begin{array}{l}\text { Blockchain Applications (payments, lending, investment, etc.) } \\
\text { are currently immature and in exploratory phases in the } \\
\text { financial services sector which make it more complex and } \\
\text { difficult to undertake its regulation }\end{array}$ & \\
\hline \multirow{2}{*}{ 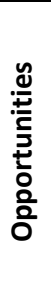 } & $\begin{array}{l}\text { Competitive } \\
\text { Advantages }\end{array}$ & $\begin{array}{l}\text { Blockchain provide sustainable competitive advantages for } \\
\text { banks in terms of financial contracts based on reduction of } \\
\text { the costs, provision of information transparency and effective } \\
\text { control over operational risks and controlling costs on the } \\
\text { network and financial transactions }\end{array}$ & \multirow[t]{2}{*}{$\begin{array}{l}\text { Vovchenko et al., } \\
\text { 2017; Yudina, } 2016\end{array}$} \\
\hline & $\begin{array}{l}\text { New Services } \\
\text { Formation }\end{array}$ & Blockhain will help banks form new services in the future. & \\
\hline
\end{tabular}

Table 3: Blockchain Cost, Benefits, Risks and Opportunities Analysis Framework for Banking and Finance Services

In order to understand the application of blockchain technology and the complexities involved in the adoption process, this study uses cost, benefit, risk and opportunity framework to highlight the factors that influence the adoption of blockchain in business and finance sector (see table 3). Blockchains are already transforming many traditional banking practices in several countries with offering benefits such as privacy, transparency, immutability, improved transaction security and faster transfer of money at a lower cost both at national and international levels (Lee and Shin, 2017). Furthermore, blockchain can be used to create trust and reduce fraud (Mainelli \& Smith, 2015; Mcai \& Zhui, 216). In addition to these benefits, blockchain technology offers opportunities for banks to gain a competitive advantage in terms of economy virtualisation over their competitors and introduce new services in future. Although blockchains may bring enormous benefits and opportunities to banking industry and give birth to a whole new generation of services ( $\varnothing$ lnes et al., 2017), there remains significant risk and cost implication of adopting the technology (Atzori, 2015; ØInes et al., 2017). As shown in Table 3, various risk factors such as scalability, security risks, interoperability reversibility and regulatory risks are some of the main challenges 
facing blockchain technology. Also, operating cost (transaction costs, energy costs, storage costs) of blockchain technology are some of the other challenges for banks. Such issues need to be taken into consideration before the mass adoption of these technologies in this field. Nevertheless, most research has been focused on addressing the technological challenges, and many initiatives remain in their infancy. As such, there is a need for a holistic understanding of the various aspects of cost, benefits, risk and opportunities to create blockchain applications that work for banking and finance sector.

Several insights can be drawn from this initial study of understanding of the application of blockchain technology to both theory and practice. From a theoretical stance, given blockchain's ability to disrupt the banking and finance sector, this paper makes a valuable contribution to the literature. Since blockchain challenges every aspect of the financial sector, this paper represents a comprehensive understanding of insights from the literature and classification of challenges into four categories: cost, benefits, risks and opporutnities. The practical implications of this study is to help the decision making process of practitioners and managers at the traditional banking and finance organizations. The results of this study also have important managerial implications which can allow managers at banking and finance organizations to better manage and organize the successful adoption of blockchain technology.This study further helps bank managers reduce risks and related blockchain adoption challenges by analyzing the taxonomy given, which identifies important factors. This study explores prospects for fintech organisation's new entrants to achieve competitive advantages by embracing blockchain technology. 
There are some limitations which future research can address. By utilising the current

state of the art in this specific research domain, this study proposed benefits, opportunities, costs, risks framework; future research needs to validate the framework empirically. This study focused on the banking and finance sector. Therefore future research should use the framework and focus on other sectors. This study outlined several challenges that affect the adoption of blockchain technology; future research should look into providing solutions for these issues.

\section{REFERENCES}

Accenture (2017). Banking on Blockchain: A value analysis for investment banks. Available via: https://www.accenture.com/us-en/insight-banking-on-blockchain (accessed 13 September 2019).

Accenture digital (2017) Join The Blockchain Party: How banks are building a real-time global payment network, https://www.accenture.com/us-en/insight-blockchaintechnology-how-banks-building- real-time

Al-Saqaf, W., \& Seidler, N. (2017). Blockchain technology for social impact: opportunities and challenges ahead. Journal of Cyber Policy, 2(3), 338-354.

Arnold, M. (2017) Five ways banks are using blockchain, https://www.ft.com/content/615b3bd8-97a9-11e7- a652-cde3f882dd7b

Attaran, M., \& Gunasekaran, A. (2019). Applications of Blockchain Technology in Business: Challenges and Opportunities. Springer Nature.

Atzori, M. (2015). Blockchain technology and decentralized governance: Is the state still necessary?. Available at SSRN 2709713.

Available via: https://www.forbes.com/sites/jasonbloomberg/2018/02/24/

Bauer, K., \& Hein, S. E. (2006). The effect of heterogeneous risk on the early adoption of Internet banking technologies. Journal of Banking \& Finance, 30(6), 1713-1725.

Bauerle, N. (2018). What are Blockchain's Issues and Limitations? Available via: https://www.coindesk.com/information/blockchains-issues-limitations/ (accessed 13 September 2019).

Bloomberg, J. (2018). Don't Let Blockchain Cost Savings Hype Fool You.

Braun, V., \& Clarke, V. (2006). Using thematic analysis in psychology. Qualitative Research in Psychology, 3, 77-101.

Caplen, B. (2018). Blockchain: where it works, where it doesnt. Available via: https://www.thebanker.com/Comment-Profiles/Editor-s-Blog/ Blockchain-where-itworks-where-it-doesn-t (accessed 13 September 2019). 
Cermeño, J. S. (2016). Blockchain in financial services: Regulatory landscape and future challenges for its commercial application. BBVA Research, Madrid, Spain. http://www.smallake.kr/wp-content/uploads/2017/01/WP 16-20.pdf

Clohessy, T., \& Acton, T. (2019). Investigating the influence of organizational factors on blockchain adoption. Industrial Management \& Data Systems.

Crosby, M., Pattanayak, P., Verma, S., \& Kalyanaraman, V. (2016). Blockchain technology: Beyond bitcoin. Applied Innovation, 2(6-10), 71.

Davis, J., Mengersen, K., Bennett, S., \& Mazerolle, L. (2014). Viewing systematic reviews and meta-analysis in social research through different lenses. SpringerPlus, 3 , 511.

Deshpande, A., Stewart, K., Lepetit, L., \& Gunashekar, S. (2017). Distributed Ledger Technologies/Blockchain: Challenges, opportunities and the prospects for standards. Overview report The British Standards Institution (BSI), 1-34. dont-letblockchain-cost-savings-hype-fool-you/\#66e40c005811 (accessed 13 September 2019).

El-Haddadeh, R. (2019) The Antecedents of Digital Innovation Dynamics Impact on Technology Adoption in SMEs: The Case of Cloud Computing Services. Information Systems Frontiers, 115

European Securities and Markets Authorities (2017) The Distributed Ledger Technology Applied to Securities Markets. https://www.esma.europa.eu/sites/default/files/library/dlt report - esma50-

1121423017-285.pdf (accessed 9 December 2019).

Fan, P. S. (2018) Singapore Approach to Develop and Regulate FinTech, In Handbook of Blockchain, Digital Finance, and Inclusion, Edited by Chuen, D. L. K. and Deng, R. H. Volume 1, Academic Press, 2018, Pages 347-357, ISBN 9780128104415, London, United Kingdom

Frame, W. S., \& White, L. J. (2014). Technological change, financial innovation, and diffusion in banking (pp. 1-5). Leonard N. Stern School of Business, Department of Economics.

Guo, Y., \& Liang, C. (2016). Blockchain application and outlook in the banking industry. Financial Innovation, 2(1), 24.

Harwood-Jones, M. (2016), "Blockchain and T2S: a potential disruptor", available at: www.sc.com/.../ 2016/.../2016-06-16-BeyondBorders-Report-SCB... (accessed 9 December 2019).

Hassani, H., Huang, X., \& Silva, E. (2018). Banking with blockchain-ed big data. Journal of Management Analytics, 5(4), 256-275.

Hillsberg, A. (2018). Can Blockchain Technology Impact Banking? We Analyse this Important Trend. Available via: https://www.comparethecloud.net/articles/ canblockchain-technology-impact-banking-we-analyse-this-important-trend/ (accessed 13 September 2019).

lansiti, M., \& Lakhani, K. (2017). R.(2017). The truth about blockchain. Harvard Business Review, 9. 
Kiayias, A., \& Panagiotakos, G. (2016). On trees, chains and fast transactions in the blockchain, 2016. URL https://eprint. iacr. org/2016/545. pdf.

Kosba, A., Miller, A., Shi, E., Wen, Z., \& Papamanthou, C. (2016, May). Hawk: The blockchain model of cryptography and privacy-preserving smart contracts. In 2016 IEEE symposium on security and privacy (SP) (pp. 839-858). IEEE.

Kshetri, N. (2017). Blockchain's roles in strengthening cybersecurity and protecting privacy. Telecommunications policy, 41(10), 1027-1038.

Kshetri, N. (2018). 1 Blockchain's roles in meeting key supply chain management objectives. International Journal of Information Management, 39, 80-89.

Larios-Hernández, G. J. (2017) Blockchain entrepreneurship opportunity in the practices of the unbanked. Business Horizons, 60(6), 35-46.

Lee, I. and Shin, Y. J. (2018) Fintech: Ecosystem, business models, investment decisions, and challenges. Business Horizons, 61(1), 35-46.

Liberati, A., Altman, D. G., Tetzlaff, J., Mulrow, C., Gøtzsche, P. C., loannidis, J. P. A., ... Moher, D. (2009). The PRISMA statement for reporting systematic reviews and metaanalyses of studies that evaluate health care interventions: Explanation and elaboration. Annals of Internal Medicine, 151, W-65

Mansfield-Devine, S. (2017). Beyond Bitcoin: using blockchain technology to provide assurance in the commercial world. Computer Fraud \& Security, 5, 4-18

Marr, B. (2017). Practical Examples Of How Blockchains Are Used In Banking And The Financial Services Sector. Available via: https://www.forbes.com/sites/bernardmarr/2017/08/10/ practical-examples-ofhow-blockchains-are-used-in-banking-and-the-financial-services-sect \#f1b33831a116 (accessed 13 September 2019).

Marsal-Llacuna, M. L. (2018). Future living framework: Is blockchain the next enabling network?. Technological Forecasting and Social Change, 128, 226-234.

Mason, J. (2017) Why Blockchain will revolutionize the banking industry, https://bravenewcoin.com/news/why-blockchain-will-revolutionize-the-bankingindustry/

Mearian, L. (2017) Blockchain gains traction in FinTech as payment networks emerge, https://www.computerworld.com/article/3234192/financial-it/blockchain-gainstraction-in-fintech-as- payment-networks-emerge.html

Mendling, J., Weber, I., Aalst, W. V. D., Brocke, J. V., Cabanillas, C., Daniel, F., ... \& Gal, A. (2018). Blockchains for business process management-challenges and opportunities. ACM Transactions on Management Information Systems (TMIS), 9(1), 1-16.

Meola, A. (2017). How banks and financial institutions are implementing blockchain technology. Available via: http://uk.businessinsider.com/ blockchain-technologybanking-finance-2017-9 (accessed 9 December 2019).

Ngai, J. L. (2016). Blockchain-Disrupting the Rules of the Banking Industry [J]. Report by McKinsey, 5 . 
Ngo, D. (2017). Accenture: Blockchain to Reduce Banks Infrastructure Costs by $30 \%$. Available via: https://coinjournal.net/ Accenture-blockchain-reduce-banksinfrastructure-costs/. (accessed 5 December 2019).

$\varnothing$ Ines, S. (2016). Beyond Bitcoin Enabling Smart Government Using Blockchain Technology. In H.J., Scholl et al. (Eds). Proceedings of the International Conference on Electronic Government, EGOV2016. Springer LNCS vol. 9820. pp. 253-264.

Osman, I. H., Anouze, A. L., Irani, Z., Al-Ayoubi, B., Lee, H., Balcı, A., ... \& Weerakkody, V. (2014). COBRA framework to evaluate e-government services: A citizen-centric perspective. Government information quarterly, 31(2), 243-256.

Park, J. H., \& Park, J. H. (2017). Blockchain security in cloud computing: Use cases, challenges, and solutions. Symmetry, 9(8), 164.

Pazaitis, A., Filippi, P. D, Kostakis, V. (2017) Blockchain and value systems in the sharing economy: The illustrative case of Backfeed. Technological Forecasting and Social Change, 105-115

Pennathur, A. K. (2001). "Clicks and bricks":: e-Risk Management for banks in the age of the Internet. Journal of banking \& finance, 25(11), 2103-2123.

Peters, G. W., \& Panayi, E. (2016). Understanding modern banking ledgers through blockchain technologies: Future of transaction processing and smart contracts on the internet of money. In Banking Beyond Banks and Money (pp. 239-278). Springer International Publishing

Queiroz, M. M., \& Wamba, S. F. (2019). Blockchain adoption challenges in supply chain: An empirical investigation of the main drivers in India and the USA. International Journal of Information Management, 46, 70-82.

Shen, L. (2016). Blockchain will be used by 15\% of Big Banks by 2017. 2016-1026], http://fortune.com/2016/09/28/blockchain-banks-2017.

Snyder, H. (2019). Literature review as a research methodology: An overview and guidelines. Journal of Business Research, 104, 333-339.

Swan, M. (2019). Blockchain Economic Networks: Economic Network TheorySystemic Risk and Blockchain Technology. In Business Transformation through Blockchain (pp. 3-45). Palgrave Macmillan, Cham.

Tapscott, D. and Tapscott, A. (2016), Blockchain Revolution: How The Technology Behind Bitcoin is Changing Money, Business, and the World, Penguin Random House, New York, NY.

Torraco, R. J. (2005). Writing integrative literature reviews: Guidelines and examples. Human Resource Development Review, 4, 356-367.

van Engelenburg, S., Janssen, M., \& Klievink, B. (2018, July). A blockchain architecture for reducing the bullwhip effect. In International Symposium on Business Modeling and Software Design (pp. 69-82). Springer, Cham.

Vovchenko, N. G., Andreeva, A. V., Orobinskiy, A. S., \& Filippov, Y. M. (2017). Competitive advantages of financial transactions on the basis of the blockchain technology in digital economy. European Research Studies, 20(3B), 193. 
Vranken, H. (2017). Sustainability of bitcoin and blockchains. Current Opinion in Environmental Sustainability, 28, 1-9

Vukolić, M. (2015, October). The quest for scalable blockchain fabric: Proof-of-work vs. BFT replication. In International workshop on open problems in network security (pp. 112-125). Springer, Cham.

Wang, S., Ouyang, L., Yuan, Y., Ni, X., Han, X., \& Wang, F. Y. (2019). Blockchain-enabled smart contracts: architecture, applications, and future trends. IEEE Transactions on Systems, Man, and Cybernetics: Systems, 49(11), 2266-2277.

Wong, G., Greenhalgh, T., Westhorp, G., Buckingham, J., \& Pawson, R. (2013). RAMESES publication standards: Meta-narrative reviews. BMC Medicine, 11, 20.

Yeoh, P. (2017) "Regulatory issues in blockchain technology", Journal of Financial Regulation and Compliance, Vol. 25 Issue: 2, pp.196-208

Yudina, T.N., 2016. Comprehension of Digital Economy // Theoretical Economics, 3. P. 12.

Zheng, Z., Xie, S., Dai, H. N., Chen, X., \& Wang, H. (2018). Blockchain challenges and opportunities: A survey. International Journal of Web and Grid Services, 14(4), 352375.

Zhu, H., \& Zhou, Z. Z. (2016). Analysis and outlook of applications of blockchain technology to equity crowdfunding in China. Financial innovation, 2(1), 29.

Zyskind, G., \& Nathan, O. (2015, May). Decentralizing Privacy: Using blockchain to protect personal data. In 2015 IEEE Security and Privacy Workshops (pp. 180-184). IEEE.

\section{Acknowledgement}

This publication was made possible by NPRP grant \# [11S-0117-180325] from the Qatar National Research Fund (a member of Qatar Foundation). The findings achieved herein are solely the responsibility of the author[s]. 